Article

\title{
Spatiotemporal Evolution of Entrepreneurial Activities and Its Driving Factors in the Yangtze River Delta, China
}

\author{
Haipeng Zhang ${ }^{1,2,3}\left(\mathbb{D}\right.$, Wei Chen ${ }^{1,2, *(\mathbb{D})}$ and Zhigao Liu ${ }^{1,2,3}$ \\ 1 Institute of Geographic Sciences \& Natural Resources Research, Chinese Academy of Sciences, \\ Beijing 100101, China; zhanghp.19b@igsnrr.ac.cn (H.Z.); liuzhigao@igsnrr.ac.cn (Z.L.) \\ 2 Key Laboratory of Regional Sustainable Development Modeling, Chinese Academy of Sciences, \\ Beijing 100101, China \\ 3 College of Resource and Environment, University of Chinese Academy of Sciences, Beijing 100049, China \\ * Correspondence: chenw@igsnrr.ac.cn
}

check for updates

Citation: Zhang, H.; Chen, W.; Liu, Z. Spatiotemporal Evolution of Entrepreneurial Activities and Its Driving Factors in the Yangtze River Delta, China. Land 2022, 11, 216. https://doi.org/10.3390/ land11020216

Academic Editors: Wei Sun, Zhaoyuan Yu, Kun Yu, Weiyang Zhang and Jiawei Wu

Received: 2 January 2022

Accepted: 28 January 2022

Published: 30 January 2022

Publisher's Note: MDPI stays neutral with regard to jurisdictional claims in published maps and institutional affiliations.

Copyright: (C) 2022 by the authors. Licensee MDPI, Basel, Switzerland. This article is an open access article distributed under the terms and conditions of the Creative Commons Attribution (CC BY) license (https:// creativecommons.org/licenses/by/ $4.0 /)$.

\begin{abstract}
The purpose of this paper is to reveal the spatiotemporal evolution of entrepreneurial activities in the local municipalities of the Yangtze River Delta at long timescales from a geographic perspective and to reveal the underlying factors driving such evolution. The ontology of entrepreneurial activities-startups-was chosen as the object of this study, and the developmental characteristics of entrepreneurial activities in the region since 2001 were explored in two dimensions: time series changes and spatial evolution. The driving mechanism was further explored using the geographical detector. The results showed that: (1) Intensive entrepreneurial activities have been underway in the Yangtze River Delta since the beginning of the 21st century. The entrepreneurial process has undergone a stable period of slow growth (2001-2013), as well as one of rapid growth (2014-2018). The number of startups increased during this period, from 241,700 in 2001 to 1,959,600 in 2018. (2) The density of entrepreneurial activities in the Yangtze River Delta has increased since 2001. The agglomerative patterns showed developmental trends of both concentration and diffusion, forming a dotted pattern of agglomeration centered on the provincial capitals of Nanjing, Hangzhou, and Hefei and a belt of agglomeration centered on Shanghai-Suzhou-Wuxi-Changzhou. (3) High-value agglomeration of entrepreneurial activities was found to be relatively stable, and low-value agglomeration steadily weakened. Shanghai, Suzhou, and Nantong have long been part of H-H clusters, while Chizhou, Wuhu, Bozhou, Huaibei, and Huainan in Anhui have become areas of depressed entrepreneurial activities. (4) Financial strength, degree of informationization, economic foundation, innovative vitality, openness, and market demand are the main factors affecting entrepreneurial activities in the Yangtze River Delta. Entrepreneurial activities have significant spatial correlation, and areas with high entrepreneurial vitality radiate their effect to the entrepreneurial activities in the surrounding areas. The factors affecting entrepreneurial activities have multiple characteristics, and policy makers should promote entrepreneurial activities with a comprehensive vision and multi-channel efforts. The findings of this study add to the understanding of the spatial proximity characteristics of long time series of entrepreneurial activities at the municipal scale in developing countries and reveal the characteristics of the multi-factor combinations affecting them.
\end{abstract}

Keywords: entrepreneurial activity; startup; spatiotemporal variation; driving factor; Yangtze River Delta

\section{Introduction}

With the steady promotion of the entrepreneurial model of economic growth, which is characterized by resource regeneration, productivity development, and the implementation of innovation-driven development strategies, entrepreneurial activities have emerged as a major means of improving the quality and efficiency of economic growth as part of China's development as an economic powerhouse. Entrepreneurial activities can promote changes 
in the market structure and adjustments to the industrial structure, increase the supply of goods, and accelerate the development of emerging industries. Moreover, they can enhance microeconomic vitality, drive employment, increase residents' incomes, and promote orderly social mobility as well as fairness and justice in socioeconomic development [1-3]. They are thus an important force for promoting national and regional competitiveness. Technological development, accelerating the pace of technological integration into the economy, and comprehensive industrialization pose daunting challenges for China in the process of economic and social transformation and development [4]. Mature large and medium-sized enterprises face high sunk costs as well as institutional costs in the process of transformation and development. Entrepreneurial activities can accelerate technological innovation and transformation, and such activities led by startups form an important part of China's current reform and development program [5]. Therefore, promoting entrepreneurial activities is important for building an innovative economy and promoting sustainable development.

Academia has been paying attention to entrepreneurial activities for a long time. In particular, since the dawn of the 21st century, innovation and entrepreneurial activities, as the driving forces of economic growth, have emerged as the core elements of productivity across the world due to the advent of the knowledge economy and information age led by the Internet and Information Technology [6-8]. Scholars have systematically explored entrepreneurial activities, including the environmental factors affecting them $[9,10]$, the effects of entrepreneurial activities [11], the relationship between regional development models and entrepreneurial activities [12,13], entrepreneurial policies [14], the spatial distribution of entrepreneurial activities and their locational characteristics [15-19], and the interactive relationships between entrepreneurial activities and the evolution of local industrial clusters [20]. The results have provided an important reference for follow-up studies. Different disciplines focus on entrepreneurial activities with different emphases. Geographical studies focus on the occurrence and development of social phenomena from a spatial perspective [21]. However, previous studies of entrepreneurial activities have tended to focus on specific regions as containers in which entrepreneurial activities can occur, ignoring the spatial dependence or spillover effects of entrepreneurial activities on a continuous geographical scale [19]. Discussion of the factors affecting entrepreneurial activity has more often than not focused on a specific regional factor, and analysis of the impact of regional factor combinations on entrepreneurial activity from an integrated perspective is still limited and sketchy [5]. In terms of research objects, current studies have focused mostly on a single company, a certain type of industry, or a platform for entrepreneurial activities [21], and have largely ignored their overall characteristics. In the time domain, most studies have focused on entrepreneurial activities in a single year, or within a short interval [22]. In the context of spatial and geographical scales, most studies have focused on developed countries and have overlooked developing countries [23]. Such research has usually focused on a given country, province, or city and has ignored urban agglomerations or integrated regions [24].

As China's economy has moved from the stage of rapid growth to one of high-quality development, increasing attention has been paid to entrepreneurial activities [25]. In 2015, China issued the "Guiding Opinions on the Development of Makerspace Space to Promote Mass Innovation and Entrepreneurship" in order to promote entrepreneurial activities in a holistic manner so as to support China's economic growth. The Yangtze River Delta is one of China's most active areas of economic development, and one of its most open and innovative regions [26]. It has a strong industrial foundation, prominent advantages in terms of science and education, and a healthy entrepreneurial atmosphere. Moreover, the integrated development of the Yangtze River Delta has become part of China's national development strategy, and its entrepreneurial vitality occupies a pivotal strategic position in supporting the overall state of China's modernization on its path to transformation and development. 
As a whole, the Yangtze River Delta is one of the regions in China with the highest level of economic development, but the level of economic development within it is uneven, with Shanghai being the core of regional development, while Anhui Province, most of Zhejiang Province, and the northern part of Jiangsu Province belong to the periphery of the region in terms of economic development and entrepreneurial conditions [25].In terms of entrepreneurial dynamism, does this "core-edge" spatial structure still exist in the Yangtze River Delta? Can the Suzhou-Wuxi-Changzhou city belt, which is close to Shanghai, receive the high-quality entrepreneurial and innovative resources radiated from Shanghai effectively and maintain strong entrepreneurial vitality? As the most developed segment in China and the most entrepreneurially dynamic region, what are the characteristics of the factors affecting entrepreneurial activity in the Yangtze River Delta? Does the level of regional development play a dominant role in entrepreneurial dynamism? This series of problems are expected to be solved in this paper, and the authors expect that the solutions to the above problems will provide a reference for future decision-making in relation to entrepreneurial policy formulation and institutional optimization in the Yangtze River Delta, as well as provide relevant experience for the development of entrepreneurial activities in other regions of China.

Based on the above background, the purpose of this studies was to extract the data of all startups between 2001 and 2018 from the database of industrial and commercial enterprises, spatialize the startups according to their latitude and longitude, reveal the spatially divergent characteristics of entrepreneurial activities and their correlation characteristics at the municipal scale in the Yangtze River Delta, over the past 20 years with the help of exploratory spatial analysis methods from a geographic perspective, and explore the comparative characteristics of the different factor combinations affecting entrepreneurial activities in this region by way of single-factor analysis and two-factor interaction analysis using the geographical detector. The originality of the study is reflected in how it reveals the spatial proximity characteristics of entrepreneurial activities over long time scales at the city scale and the characteristics of the multi-factor combinations that affect entrepreneurial activities.

This paper is divided into six sections. The first part is an introduction; followed by a literature review; the third part introduces the case study area, research data and research methodology; the fourth part analyzes the evolutionary characteristics of entrepreneurial activities in the Yangtze River Delta in terms of their development history and spatial concentration and further explores the factors affecting them; the fifth part presents a discussion of the results; and finally, the sixth part summarizes the conclusions and suggests several policy implications.

\section{Literature Review}

The contribution of entrepreneurial activities to economic growth has been verified in various ways in the literature in different contexts, in both theoretical and positivist studies [27-30]. However, there has not been a uniform and appropriate understanding of which factors affect the development of entrepreneurial activities most significantly [31]. In the literature from different disciplinary backgrounds, researchers have proposed different ideas about the factors affecting entrepreneurial activities.

Entrepreneurial activities cannot be carried out in isolation from the specific entrepreneurial environment, and the social environment is also considered to be an important factor, including the elements of social values, customs, ethical perceptions and local culture [32]. A study of 54 regions in Europe found that regions with more positive attitudes toward entrepreneurship had higher entrepreneurial vitality [33]. Using the research framework of institutional economics, Alvarez et al. [34] analyzed how regional environmental conditions affected entrepreneurial activities at the regional level in Spain according to the gender of the entrepreneur. By comparing two Swedish cities, Sabrina and Marina [35] explored how regional culture based on industrial heritage affected entrepreneurial activities in different regions. Daymard's study [36] of the impact of gender 
bias on entrepreneurial activities finds that bias against women in India inspired the growth of some female entrepreneurs. In addition, a good social governance environment, such as a solid legal framework, a clear property rights system, clear and simple entrepreneurial procedures and other institutional conditions, also had a positive impact on entrepreneurial activities [37,38].

In addition to the entrepreneurial environment, many other factors, such as innovation, age, education level, entrepreneurship, business dynamics, financing conditions, openness and public policies, have an important impact on the development of entrepreneurial activities. Of these, innovative ability includes not only the ability to put innovative ideas into practice, but also the ability to learn new things, new processes, and new methods and to promote them into application, which is an important endogenous force for promoting entrepreneurship [39]. Gandhi et al. [40] analyzed the impact of demographic factors on entrepreneurial activity using individual-level data from the 2013 ASEAN National Entrepreneurship Consortium and found that early-stage entrepreneurs were generally more capable than mature entrepreneurs and that young entrepreneurs were generally more capable of starting a business. A questionnaire survey conducted by Borges et al. [41] for the northern region of Portugal found that education was a key element in promoting entrepreneurial motivation and that the better prepared students were for entrepreneurial activities, the more likely they were to become entrepreneurs. Entrepreneurial individuals have the initiative, creativity, and ability to take risks responsibly, and always interact positively with their environment in order to undertake successful entrepreneurial ventures [42]. Business vitality is an effective manifestation of market dynamics and competitiveness, which plays an important role in entrepreneurship, management, and the growth process of companies [43]. Funding is the cornerstone of entrepreneurial activities. Studies in Asia have found that financing conditions have a significant positive role in promoting entrepreneurial activities [44]. In the face of the opening of the global market, more efficient foreign companies can break into the domestic market. In such instances, there is the risk of foreign multinational companies monopolizing the domestic market and so the entrepreneurial vitality in corresponding fields is suppressed [45]. Salman's study [46] of countries with either efficiency-driven or innovation-driven development found that public policies to support entrepreneurial activity played an important role by improving education levels, strengthening research investment, and formulating attractive tax policies.

The conclusion to be drawn, therefore, is that previous studies of entrepreneurial activities have focused mainly on economics, management, and the social sciences, while the development of entrepreneurial activities is a process characterized by spatiotemporal constructs. Although the above-mentioned fields of studies provide a relatively solid disciplinary foundation, there is still a need to strengthen research on the spatiotemporal manifestations of entrepreneurial activities and the role played by spatiotemporal elements in their dynamic evolution [30]. Thus, there needs to be more of a geographical focus on the spatiotemporal dynamic differences in entrepreneurial activities in order to highlight geography's unique contribution to research in the field of entrepreneurship.

\section{Materials and Methods}

To reveal the spatiotemporal evolution of entrepreneurial activities and its driving factors in the Yangtze River Delta, the analytical framework was built. The authors analyzed the evolutionary characteristics of entrepreneurial activities in the Yangtze River Delta in terms of their development history and spatial concentration, and further explored the factors affecting them. The detailed research diagram is shown in Figure 1. 


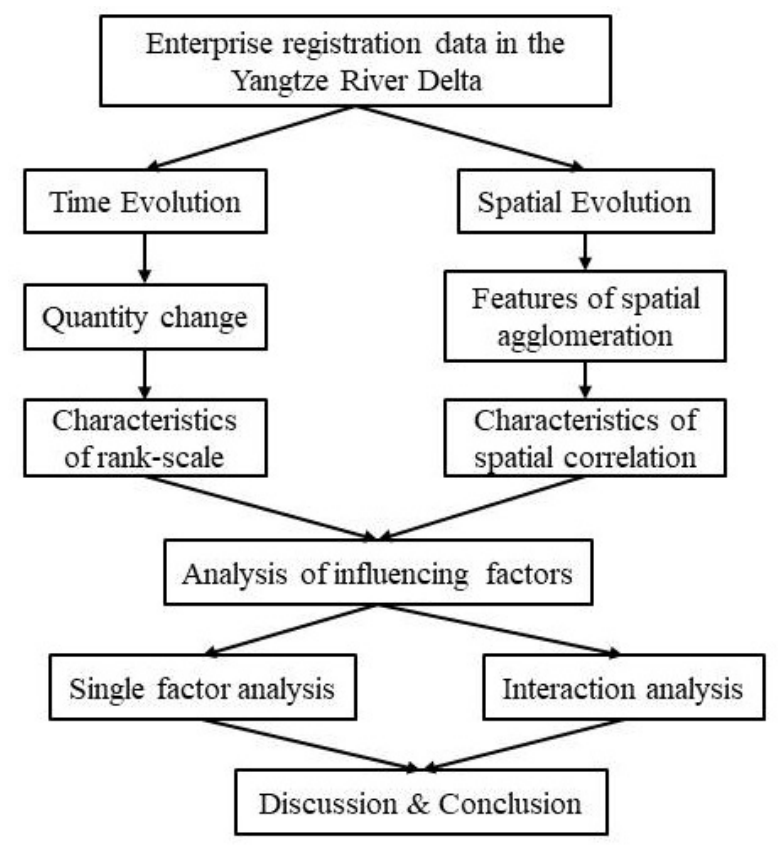

Figure 1. Technology roadmap for this study.

\subsection{Study Area}

The scope of the Yangtze River Delta region considered in this study was determined based on the "Outline of the Yangtze River Delta Regional Integration Development Plan" announced by the Chinese Central Government in 2019. It contains 41 cities in Shanghai, Jiangsu Province, Zhejiang Province, and Anhui Province (Figure 2) and covers an area of $359,100 \mathrm{~km}^{2}$, accounting for 3.73\% of China's total land area [47]. The Yangtze River Delta is in the plains of the middle and lower reaches of the Yangtze River. The southern part of Anhui Province and most of Zhejiang Province are hilly areas. The topographical conditions have shaped the spatial pattern of the delta, with a large population in the north and a small one in the south. It is among the strongest economic regions in China, with the highest population density and the largest number of towns. In 2019, its gross domestic product was CNY 23.73 trillion, accounting for $24 \%$ of China's gross domestic product, and its permanent population was 219 million, accounting for $15.7 \%$ of the country's total population [47]. The Chinese central government has identified the integrated development of the Yangtze River Delta region as part of its national development strategy, and its entrepreneurial activities and economic vitality have become distinctive indicators of China's economic development.

\subsection{Data Sources}

Data for the startups investigated in this study were taken from the Industrial and Commercial Enterprise Registration Database, which included information such as the name, office address, registered address, industrial classification, type of company, date of registration, registered capital, and geographic coordinates of each startup established in each year in China from 2001 to 2018. Four typical years, 2001, 2008, 2015, and 2018, were selected to carry out specific comparative time-space analyses. ArcGIS software was used to calibrate and transform the geographic coordinates of each startup in the database and establish a spatial point database of startups in the delta region. The relevant socio-economic data were taken from the statistical yearbooks of the three provinces and one city in the region and the statistical yearbooks of each city. Data for the administrative boundaries of the relevant provinces and cities were taken from the Resource and Environmental Science and Data Center of the Chinese Academy of Sciences (https: / /www.resdc.cn/, accessed on 25 November 2021) 


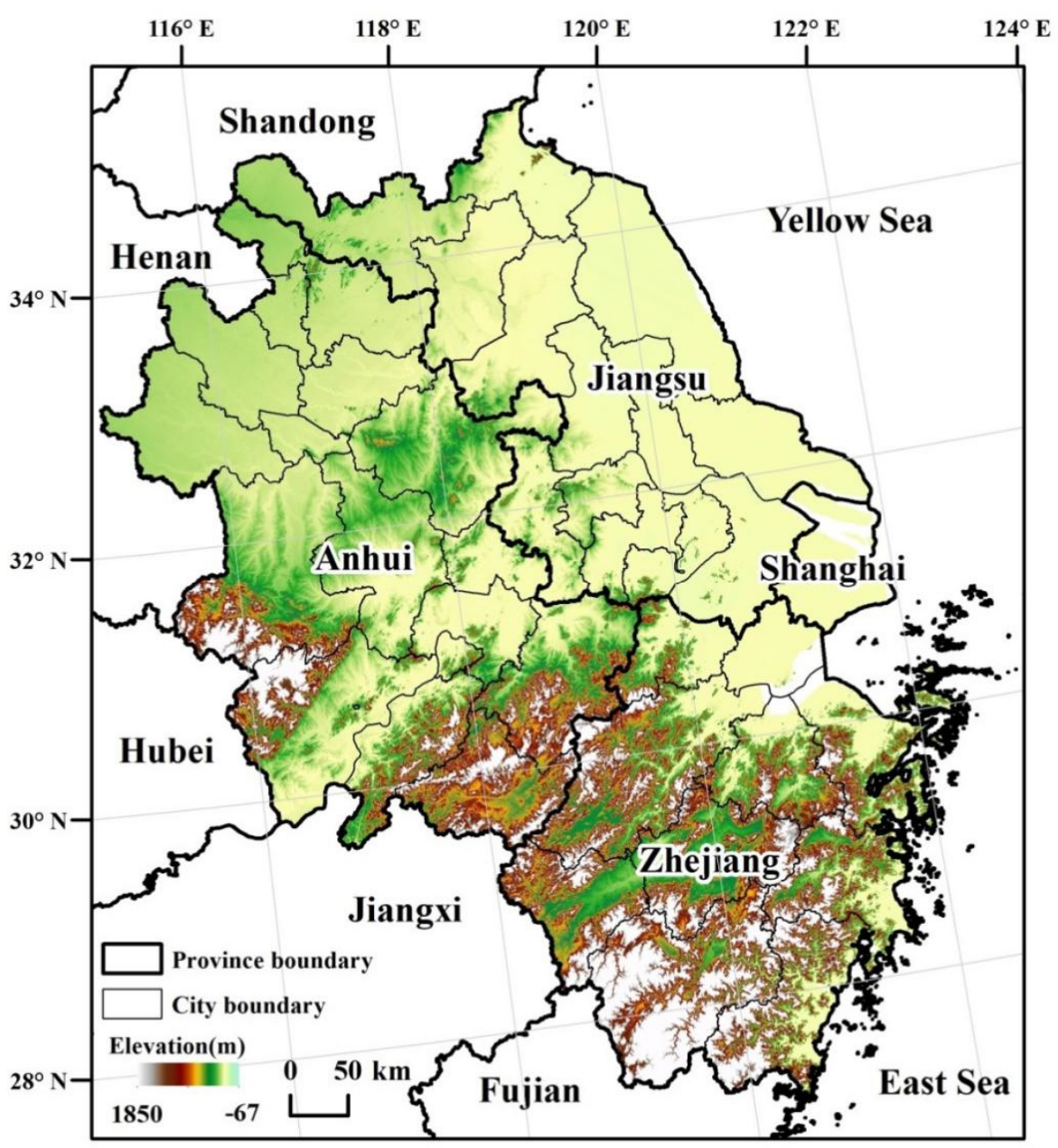

Figure 2. Geographic location of the Yangtze River Delta in China.

\subsection{Research Methods}

\subsubsection{Rank-Scale Rule}

The rank-scale rule is a method used in urban geography to explore the regular relationship between the scale of a city and its rank [48]. We used it to construct a rank-scale rule based on the number of startups:

$$
\begin{gathered}
P_{i}=\frac{P_{1}}{R_{i}^{q}} \\
\ln P_{i}=\ln P_{1}-q \ln R_{i}
\end{gathered}
$$

where $P_{i}$ is the number of startups owned by cities in the research area of the order of $i, R_{i}$ is the order of the $i$-th city, $P_{1}$ is the number of startups in the city with the most startups in the study area, and $q$ is the slope of the regression line. The larger the value of $q$ is, the more concentrated is the scale distribution of startups. The smaller the value of $q$ is, the more balanced is the distribution of startups. The number of startups in small and medium-sized cities was larger. 


\subsubsection{Kernel Density Estimation}

Kernel density estimation is a non-parametric method of estimation to describe the overall distribution of random variables [49]. We used it to describe the spatial agglomeration of startups in the Yangtze River Delta:

$$
f_{h}(x)=\frac{1}{n h} \sum_{i=1}^{n} k\left(\frac{x-x_{i}}{h}\right)
$$

In the formula, $f_{h}(x)$ is the kernel function, $h$ is bandwidth, $n$ is the total number of startups, $\left(x-x_{i}\right)$ is the distance between the observation point $x$ and the sample point $x_{i}$, and $k$ is the density function. The kernel function calculates the agglomeration of point elements in the entire study area based on the input data. The larger the value of $f_{h}(x)$ is, the denser the distribution of points.

\subsubsection{Spatial Correlation Analysis}

Spatial autocorrelation is among the most important characteristics of geographic phenomena. It refers to the feature that the attribute value of an area adjacent to the observation unit is often similar to or different from the attribute value of an observation unit compared to that of a distant area. Spatial autocorrelation includes global and local autocorrelations. Moran's I and the Local Indicator of Spatial Association (LISA) can be used to explore the global and local correlations of regional units [50]. The spatial correlation characteristics of entrepreneurial activities are the highlight of this study, and also make up for the lack of existing research that ignores the spatial dependence or spillover effects of entrepreneurial activities in a continuous geographic range. The spatial autocorrelation method can express the spatial proximity characteristics of geographical phenomena effectively, which has been widely confirmed in existing studies [26,32,49] and is a suitably effective method for the purposes of this paper. We used the queen's rule to define the matrix of spatial weights, that is, regions with common boundaries or common vertices were defined as being adjacent to each other.

\subsubsection{Geographic Detector}

Geographical detectors are an effective method for exploring the mechanism of spatial heterogeneity for multiple independent variables covariance immunity, effectively overcoming the limitations of traditional econometric statistical methods, and can explore the spatial heterogeneity of factors without too many assumptions [51]. Factor detectors can be used to identify the effects of different factors on the spatial distribution of certain types of phenomena. Their unique ability to detect factor interaction can further explore the effects of different combinations of elements on the phenomenon being investigated. The single-factor detection and factor interaction detection functions of the geographic probe are in line with the purpose of this paper in order to carry out an analysis of the combined effects of factors affecting entrepreneurial activities. Established studies have confirmed it to be an effective method for revealing the driving mechanisms of geographical phenomena [52]. We used the factor detection part of the geographic detector to explore the relationship between the number of startups $Y$ and the factors affecting them, $X$, in the Yangtze River Delta:

$$
q=1-\frac{1}{N \sigma^{2}} \sum_{h=1}^{L} N_{h} \sigma_{h}{ }^{2}
$$

where $q$ represents the decisive power of the influential factors on the spatial differentiation of entrepreneurial activities, $N$ and $N_{h}$ represent the number of startups in the research area and their level $h, \sigma^{2}$ and $\sigma_{h}{ }^{2}$, respectively, represent the variance of the number of startups in the study area and that of the number of startups in layer $h$, and $L$ is the number of categories of variable $X$. 


\section{Results}

\subsection{Changes in Time Series of Entrepreneurial Activities}

\subsubsection{Overall Quantitative Changes}

Since the beginning of the 21st century, entrepreneurial activities in the Yangtze River Delta have been intense, and the number of startups has grown exponentially (Figure 3). From 2001 to 2018, the number of startups in the region increased by more than seven times in 18 years, from 241,700 to 1,959,600. From the perspective of growth, entrepreneurial activities in the Yangtze River Delta have undergone a stable period of slow growth (2001-2013), followed by one of rapid growth (2014-2018). The development of entrepreneurial activities is closely related to the macroeconomic background and relevant national policies. The average annual growth of startups during the stable period was maintained at approximately 50,000 , and the average annual number of entrepreneurs was maintained at approximately 400,000 from 2004 to 2007. There were no significant changes in successive years, and entrepreneurial activities were quite weak during this period. Since 2009, the number of startups has increased significantly because the Yangtze River Delta has gradually emerged from the effects of the 2008 global financial crisis. Due to the national policy on innovation, entrepreneurial activities in the region entered a period of rapid growth after 2014, with an average annual addition of 200,000 startups. The entrepreneurial wave of "mass entrepreneurship and innovation" advocated by central government has provided a favorable environment for entrepreneurship in the area. Additionally, provinces and cities in the Yangtze River Delta have applied for various platforms for entrepreneurial innovation. In the three batches of national-level crowd-creation space lists recognized by the Ministry of Science and Technology from 2015 to 2016, a total of 245 companies were approved in the Yangtze River Delta region. This has provided a strong impetus to entrepreneurial activities in electronic information, smart hardware, biomedicine, and cultural creativity. The implementation of the relevant policies has greatly stimulated the entrepreneurial vitality of the Yangtze River Delta.

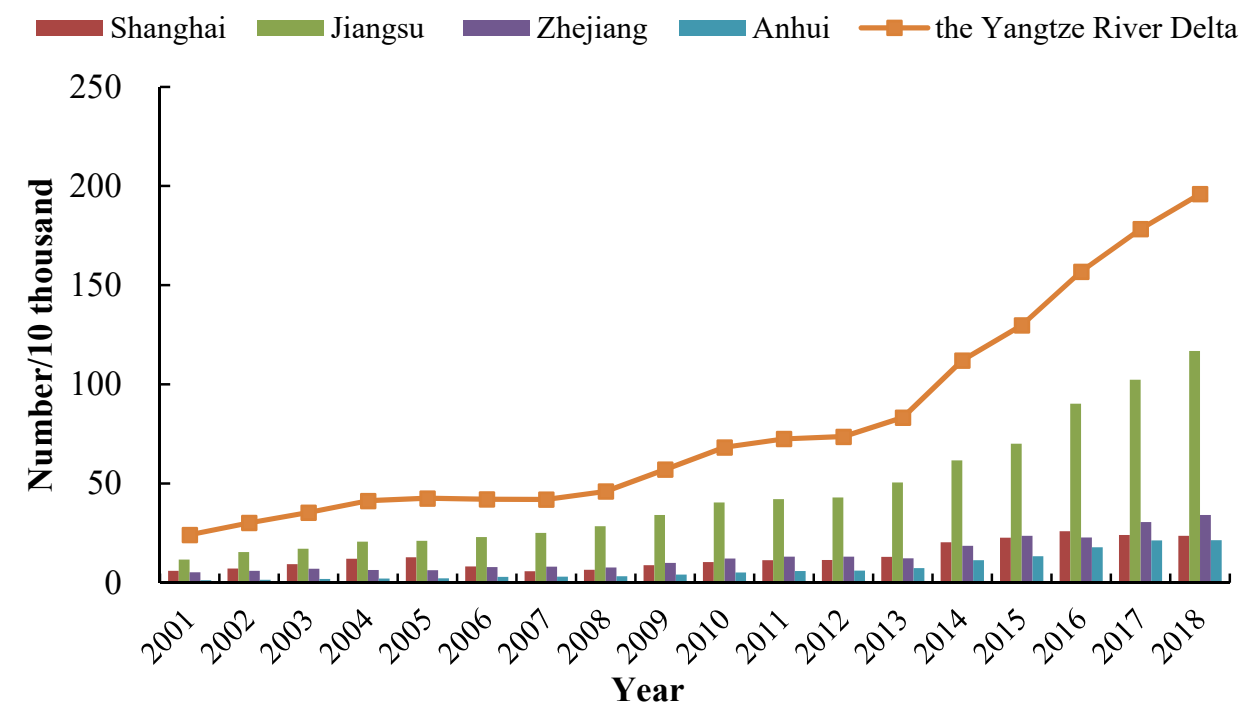

Figure 3. Changes in the number of startups in the Yangtze River Delta from 2001 to 2018.

There are significant regional differences in entrepreneurial activities across provinces and cities in the Yangtze River Delta. Jiangsu Province ranks first in terms of the number of startups, and its share of the total has increased from $48.26 \%$ in 2001 to $59.61 \%$ in 2018 . Zhejiang Province ranks second, with an increase from 52,400 startups in 2001 to 341,300 in 2018 , about $18 \%$ of the total. The number of startups in Shanghai has continued to grow, but its ratio of the total has continued to decrease from $24.68 \%$ in 2001 to $12.05 \%$ in 2018 . Anhui Province has the smallest number of startups among the three provinces and one city in the Yangtze River Delta, but its entrepreneurial vitality has continued to increase 
in the past 18 years. Its ratio of startups to those in the Delta has increased from 5.39\% to $10.93 \%$.

\subsubsection{Characteristics of Rank-Scale}

The scale of startups in cities in the Yangtze River Delta region conforms to the typical rank-scale rule. Over time, the rank-scale characteristics have developed from those of concentration to those of greater balance, and the scale of startups in small and mediumsized cities continues to increase. A diagram of the rank-scale distribution (Figure 4) shows that the goodness of fit of each annual curve is above 0.83 , which conforms to the typical rank-scale rule. The rank-scale structure presents a state of coexistence of low head and crunching. Shanghai, Suzhou, Nanjing, and Wuxi have long been at the top of the curve of the rank-scale, and have a large number of startups. However, the top-ranking cities in terms of the number of startups were all below the fitting curve, indicating their characteristics of scale were not well developed. The tail was mainly formed by Chizhou, Huaibei, Huainan, Huangshan, and Tongling in Anhui. These cities were in areas with poor economic development in the context of the region, and had limited funds, resources, and policies needed to support entrepreneurial activities. From the perspective of temporal evolution, the slope of the curve of fitting of the rank-scale has continued to increase from -1.4776 in 2001 to -1.2605 in 2018 . The rank-scale characteristics have continued to develop from a state of concentration to equilibrium, indicating that over time, the concentration of entrepreneurial activities in the Yangtze River Delta region has been weakening in the top ranking city, while the entrepreneurial vitality of small and medium-sized cities has continued to increase.
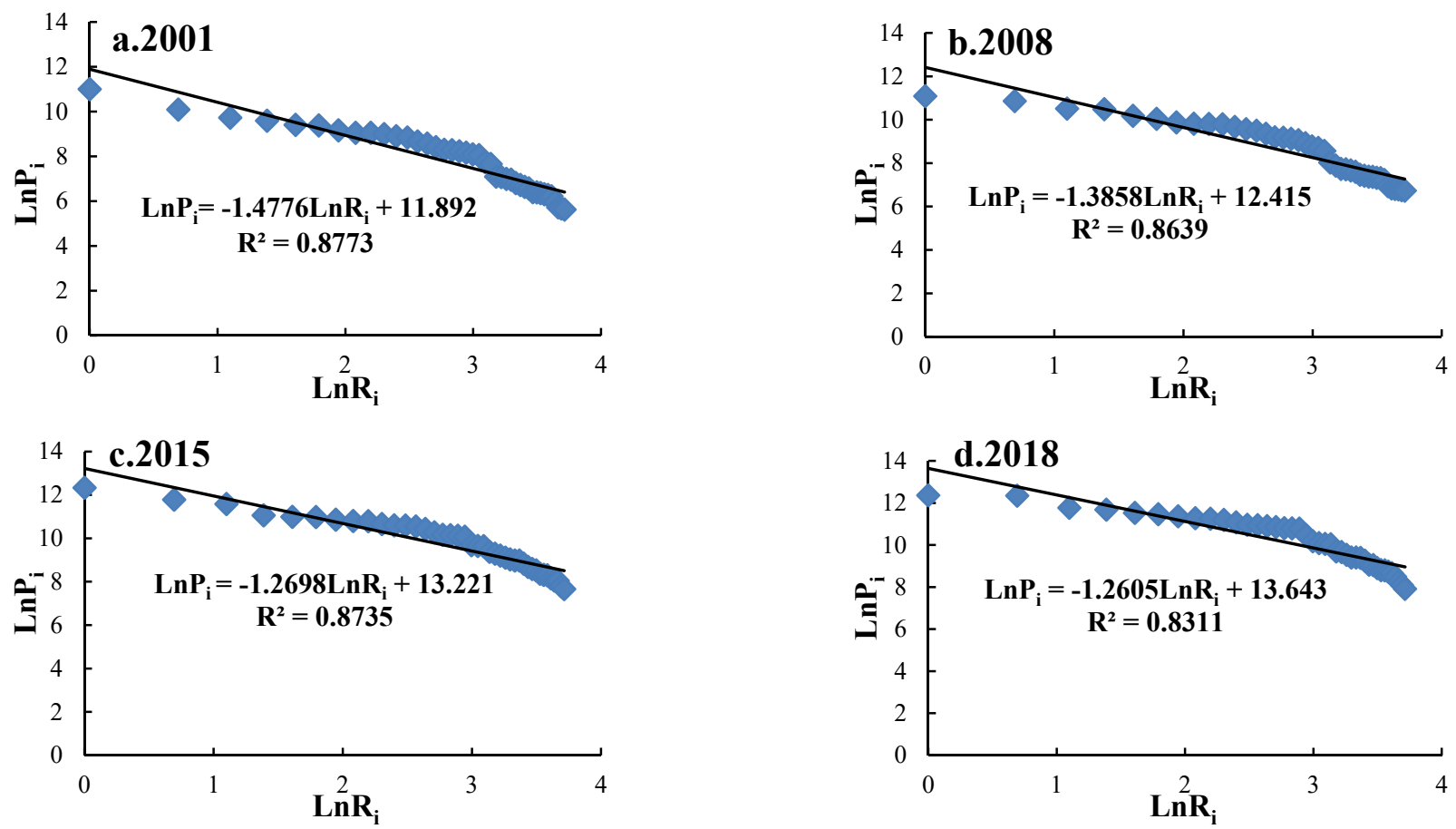

Figure 4. The rank-scale distribution of cities in the Yangtze River Delta defined by the number of startups (a) in 2001, (b) in 2008, (c) in 2015, and (d) in 2018.

\subsection{Spatial Evolution of Entrepreneurial Activities}

\subsubsection{Features of Spatial Agglomeration}

We applied data for the location of the startups to kernel density estimation in order to assess their spatial agglomeration characteristics in the Yangtze River Delta from 2001 to 2018 (Figure 5). Overall, since 2001, the spatial density distribution of startups in the region has been increasing, and their state of agglomeration has shown a developing trend 
in terms of both concentration and diffusion. While they form a dotted area centered on the provincial capital cities of Nanjing, Hangzhou, and Hefei, and a contiguous high-density strip in Shanghai-Suzhou-Wuxi-Changzhou, their range of spatial agglomeration represents a trend of spreading from the core to the peripheral areas, and from large to small and medium-sized cities.
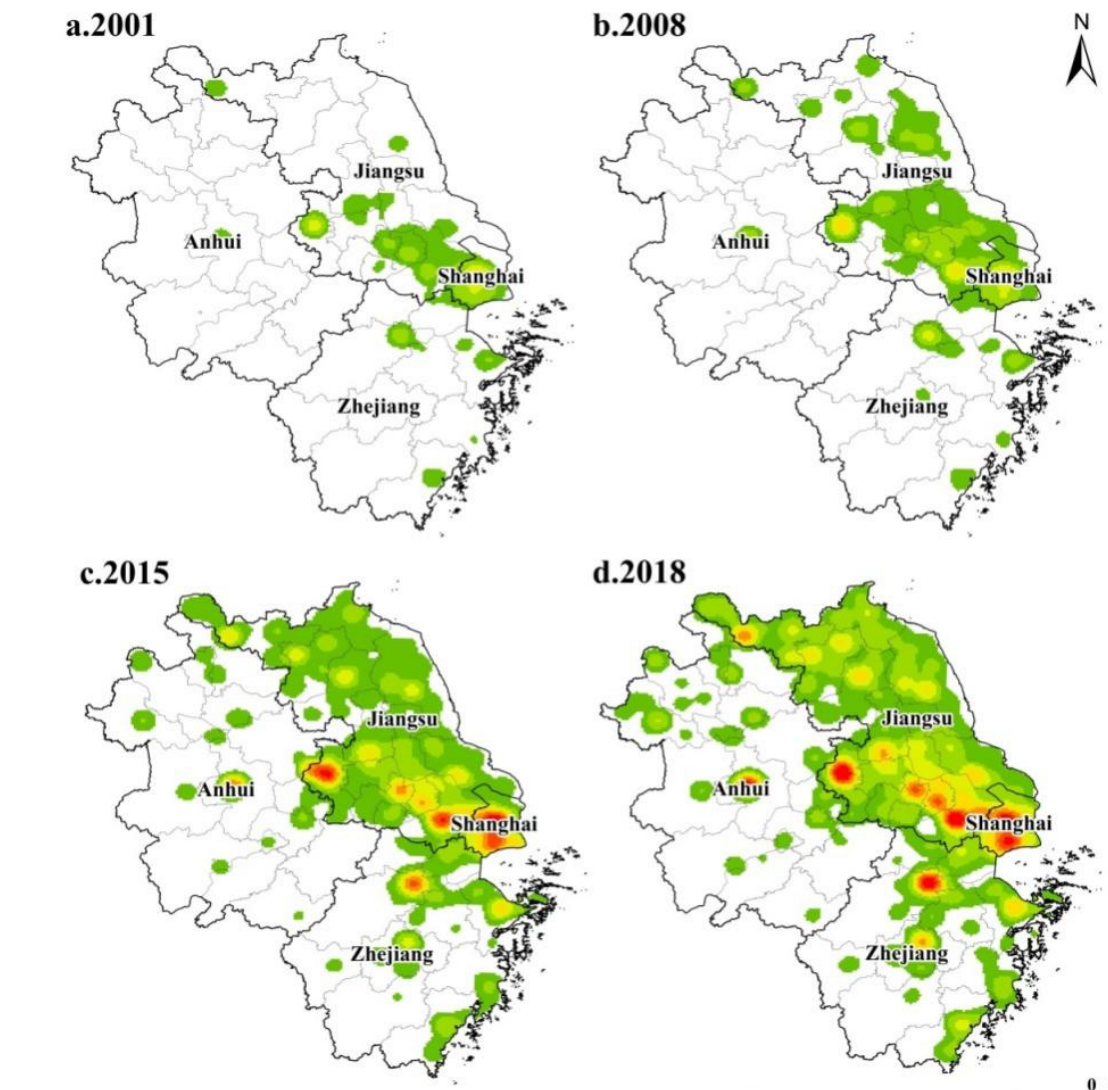

\section{d.2018}

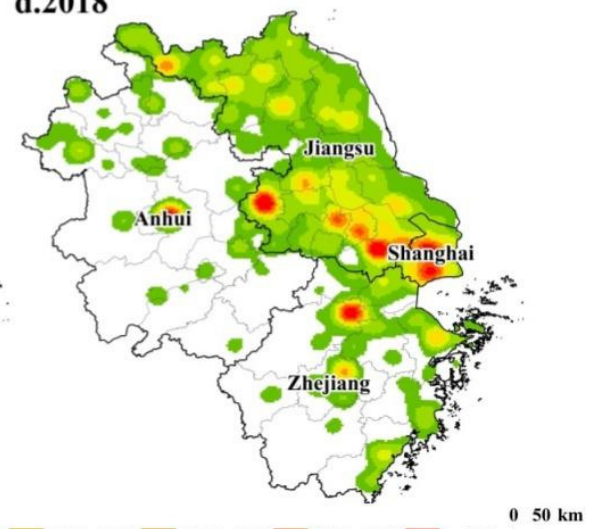

Figure 5. The spatial agglomeration status of start-ups in the Yangtze River Delta (a) in 2001, (b) in 2008, (c) in 2015, and (d) in 2018.

The peak spatial density distribution of startups in the Yangtze River Delta from 2001 to 2018 increased from 20.78 per $\mathrm{km}^{2}$ to 84.95 per $\mathrm{km}^{2}$. High-density areas continued to expand, and areas with densities below $1.89 \mathrm{pcs} / \mathrm{km}^{2}$ continued to shrink. The density distribution exhibited spatial patterns of high in the north and low in the south, and high in the east and low in the west. The spatial density distributions of Jiangsu and Shanghai continued to increase, and high-density areas showed an overall development trend. However, Anhui and Zhejiang were restricted by the level of economic development and the geographical environment, respectively. High-density areas were dotted throughout the region as a whole, and the entire area was dominated by low-density areas. From the perspective of spatial agglomeration, the provincial capitals of Nanjing, Hangzhou, and Hefei underwent large increases in their densities in 18 years to form dotted areas of agglomeration for entrepreneurial activities. Shanghai, Suzhou, Wuxi, and Changzhou are not only geographically adjacent to each other, but the spatial densities of their startups were also the highest in the region, forming a belt-shaped high-density area of concentration. Entrepreneurial activities were concentrated in major cities, and the density of startups in cities with strong economic vitality in the periphery increased during the period of study, with several regional dense cores appearing. Xuzhou in the north of Jiangsu Province, Jinhua in central Zhejiang Province, Ningbo in the east, and Wenzhou in the south all recorded increased densities. This overall pattern reflects the 
development of entrepreneurial activities in cities at different levels of development in the Yangtze River Delta.

\subsubsection{Characteristics of Spatial Correlation}

The entrepreneurial activities of cities in the Yangtze River Delta have shown significant characteristics of spatial correlation. From 2001 to 2018, values of the Global Moran's I index of the four cross-sectional startups in the region were all greater than zero, and their $p$-value was all less than 0.01 , thus passing the significance test at the $1 \%$ level. This shows that entrepreneurial activities of cities in the Yangtze River Delta have shown a significant positive spatial correlation; that is, high-high and low-low characteristics of agglomeration of entrepreneurial activities have been observed (Table 1). From the perspective of temporal evolution, Moran's I index showed increased volatility, indicating that the characteristics of spatial correlation of entrepreneurial activities in the Yangtze River Delta have shown a trend of increased volatility.

Table 1. Global Moran's I of startups in the Yangtze River Delta from 2001 to 2018.

\begin{tabular}{ccccc}
\hline Year & $\mathbf{2 0 0 1}$ & $\mathbf{2 0 0 8}$ & $\mathbf{2 0 1 5}$ & $\mathbf{2 0 1 8}$ \\
\hline Moran's I & 0.2463 & 0.3858 & 0.2558 & 0.3516 \\
Z-Score & 3.3230 & 3.8785 & 2.9062 & 3.5444 \\
$p$-Value & 0.0009 & 0.0001 & 0.0037 & 0.0004 \\
\hline
\end{tabular}

As shown in Figure 6, the clustering obtained using LISA at the prefecture-level cityscale revealed high-value and low-value agglomerations of entrepreneurial activities in some regions of the Yangtze River Delta. High-value agglomeration in the region was relatively stable, while low-value agglomeration gradually weakened. The number of $\mathrm{H}-\mathrm{H}$ clusters was relatively stable, at approximately three. The number of L-L clusters gradually decreased from seven in 2001 to one in 2018, and the numbers of H-L clusters and L-H clusters were relatively small. From the perspective of the connections formed by each city, Shanghai, Suzhou, and Nantong have long belonged to H-H clusters. Shanghai is a municipality directly under the control of the Central Government of China and is the country's center of economic, financial, trade-related, and technological innovation. It is economically strong, and has an excellent environment for entrepreneurship and innovation. It also has the highest entrepreneurial vitality in the Yangtze River Delta. Suzhou and Nantong are adjacent to Shanghai, and their economic development and technological innovation are driven by it due to the spillover effect of Shanghai's developmental resources. Chizhou and Wuhu in southwest Anhui and Bozhou, Huaibei, and Huainan in northwest Anhui lag behind other parts of the region. They have limited degrees of innovation, few entrepreneurial platforms, and imperfect policy support. These areas thus have depressed entrepreneurial activities, and are classed as L-L agglomeration areas. Hefei, the capital of Anhui Province, and Hangzhou, the capital of Zhejiang Province, have gradually developed into H-L clusters because economic development in provincial capital cities is generally at the forefront of each province's development. At the same time, these cities enjoy advantageous resources in terms of politics, talent, and technological innovation, and their entrepreneurial vitality is generally higher than that of surrounding cities. Jiaxing and Huzhou in Zhejiang Province are located between Shanghai and Hangzhou. As their developmental strength and entrepreneurial vitality are significantly lower than those of Shanghai and Hangzhou, they have depressed entrepreneurial activities, and an L-H agglomeration area. 

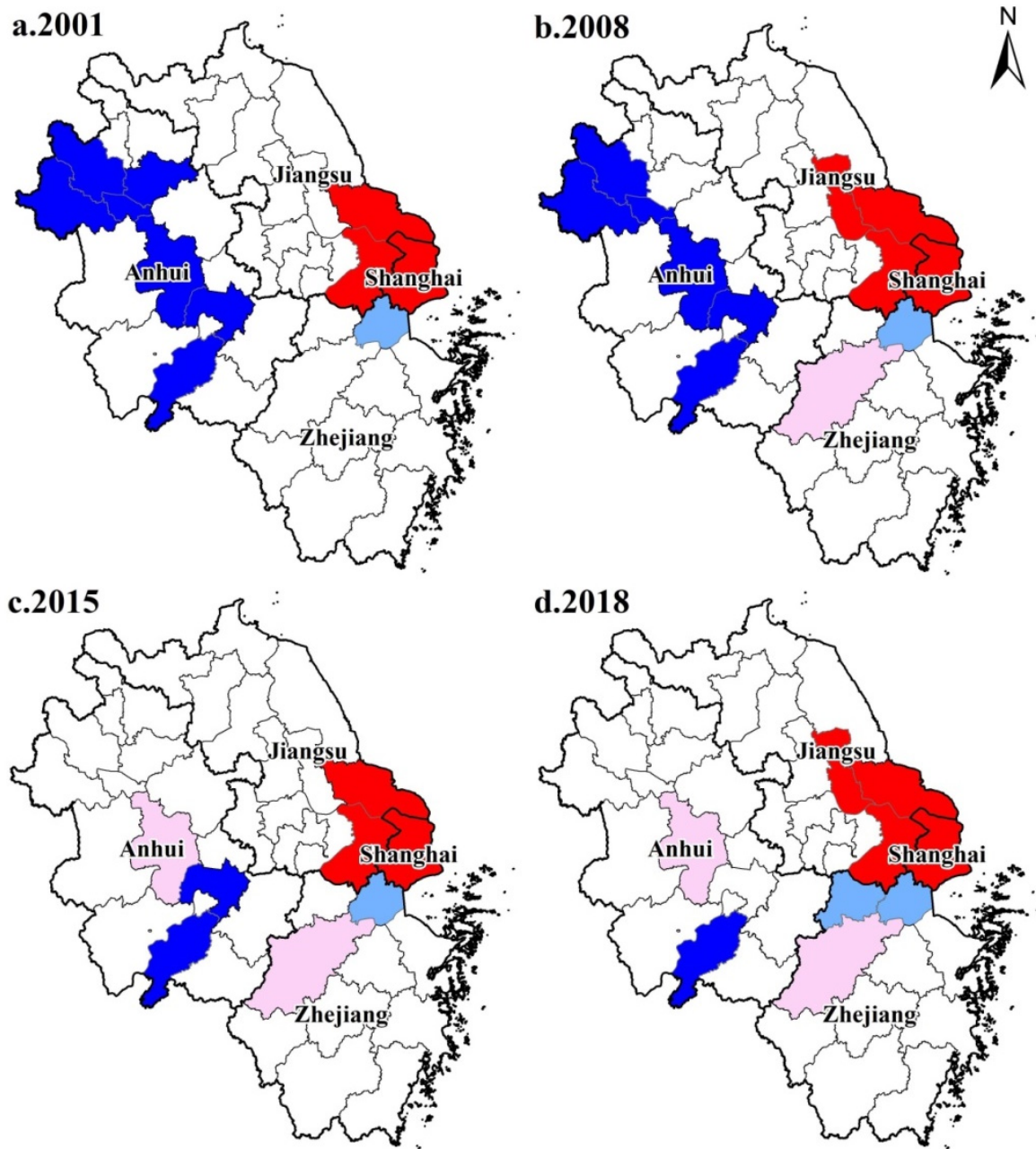

d.2018

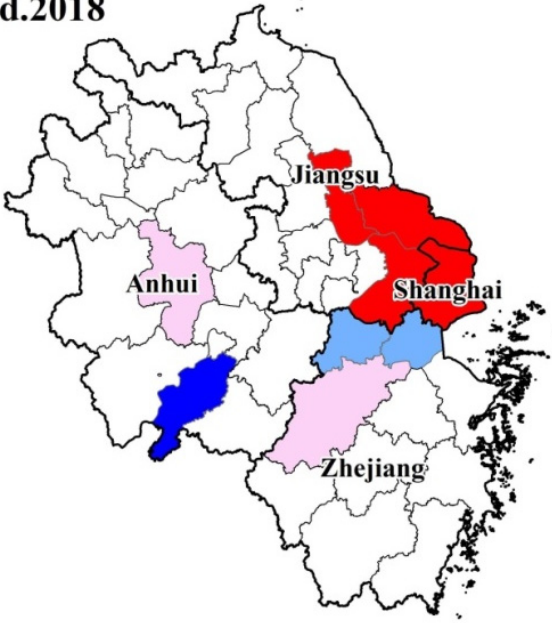

$\square$ Not Significant High-High

High-Low

Low-High

Low-Low L

Figure 6. Map of LISA agglomeration of startups in the Yangtze River Delta (a) in 2001, (b) in 2008, (c) in 2015, and (d) in 2018.

\subsection{Analysis of Driving Factors}

\subsubsection{Selection of Driving Factors}

The development of entrepreneurial activities has strong regional roots and requires a suitable combination of various frameworks and systemic conditions conducive to entrepreneurship [53]. These include the level of regional economic development, the characteristics of the industrial structure, the degree of openness to development, the state of market demand, the degree of technological innovation, and the conditions of human capital [54-57]. Following scientific and systematic principles, and also those of objectivity and data availability, we used the per capita and proportional indicators as the factors affecting entrepreneurial activities in order to adequately reflect the impact of differences in the relative efficiencies of cities. Nine indicators were selected based on four aspects: economic development, degree of openness, social environment, and innovation-related conditions. Per capita GDP (X1) was used to characterize the economic foundation, the ratio of the output of tertiary industry (X2) was used to characterize the industrial structure, and the year-end loan balance of financial institutions per capita (X3) was used to characterize financial strength. The degree of openness was characterized by the total ratios of imports and exports to GDP (X4). The total number of postal and telecommunications businesses per capita (X5) was used to characterize the degree of informationization, total retail sales of consumer goods per capita (X6) was used to characterize market demand, and the density 
of the highway network (X7) was used to characterize the convenience of the transportation infrastructure. The ratio of employees at the end of the year (X8) was used to characterize the extent of available human resources, and the number of patents granted per 10,000 people (X9) was used to represent the vitality of innovation. Based on the statistical yearbooks of cities in the region in the relevant years, data on four typical years were obtained, and tools for factor detection and interactive detection in the geo-detector were used to explore the explanatory power of single factors as well as the characteristics of interaction on the entrepreneurial activities among various driving factors.

\subsubsection{Single Factor Analysis}

The results of the single-factor detection (Table 2) showed that over time, the factors affecting entrepreneurial activities in the Yangtze River Delta have gradually shifted from multiple to concentrated. Financial strength, degree of openness, degree of informationization, and market demand were the factors exerting the greatest effects. The economic foundation and industrial structure had low explanatory power, underwent fluctuations, and exhibited decreasing levels of significance in testing. Both indicators failed the test of significance in 2008 and 2018. The overall convenience of transportation, availability of human resources, and vitality of innovation failed the test of significance at the $10 \%$ level. Financial strength, degree of openness, degree of informationization, and market demand significantly affected entrepreneurial activities. The explanatory power of financial strength and the degree of informationization both increased, from 0.5982 and 0.5589 in 2001 to 0.6369 and 0.6428 in 2018 , respectively. Although the explanatory power of market demand decreased during this period, its overall explanatory power remained high. The explanatory power of the degree of openness dropped significantly, from 0.7528 in 2001 to 0.2929 in 2018.

Table 2. Results of factors affecting entrepreneurial activities in the Yangtze River Delta.

\begin{tabular}{cccccccccc}
\hline Year & $\mathbf{X 1}$ & $\mathbf{X 2}$ & $\mathbf{X 3}$ & $\mathbf{X} 4$ & $\mathbf{X 5}$ & $\mathbf{X 6}$ & X7 & X8 & X9 \\
\hline 2001 & $0.6404^{* * *}$ & $0.3331^{*}$ & $0.5982^{* * *}$ & $0.7528^{* * *}$ & $0.5589^{* * *}$ & $0.8372^{* * *}$ & 0.1959 & 0.2151 & $0.5000^{* * * *}$ \\
2008 & $0.3242^{* * *}$ & $0.2449^{* * *}$ & $0.5306^{* * *}$ & $0.5442^{* * *}$ & $0.5686^{* *}$ & $0.5049^{* * *}$ & 0.1930 & 0.1204 & 0.1911 \\
2015 & $0.2580^{*}$ & $0.5332^{* * *}$ & $0.5981^{* * *}$ & $0.6941^{* * *}$ & $0.7197^{* * *}$ & $0.2785^{*}$ & 0.1723 & 0.1148 & 0.1740 \\
2018 & 0.4176 & $0.1977^{* * *}$ & $0.6369^{* *}$ & $0.2929^{*}$ & $0.6428^{* * *}$ & $0.5356^{* * *}$ & 0.0650 & $0.2494^{*}$ & 0.2205 \\
\hline
\end{tabular}

Note: ${ }^{*}, * *$, and $* * *$ indicate significance levels of $10 \%, 5 \%$, and $1 \%$, respectively. Per capita GDP $(\mathrm{X} 1)$, the ratio of the output of tertiary industry (X2), the year-end loan balance of financial institutions per capita $(\mathrm{X} 3)$, the total ratios of imports and exports to GDP (X4), the total number of postal and telecommunications businesses per capita (X5), total retail sales of consumer goods per capita (X6), the density of the highway network (X7), the ratio of employees at the end of the year (X8), the number of patents granted per 10,000 people (X9).

\subsubsection{Interaction Analysis}

From the perspective of two-factor interaction (Figure 7), the explanatory power of interactions between the influential factors was significantly higher than that of any single-factor. The types of interactions consisted of two-factor enhancement and nonlinear enhancement, with an equal number of instances of each. A single or single-type element controlled the spatial differentiation of entrepreneurial activities. The interaction between any pair of influential factors increased the explanatory power of spatial differentiation of their entrepreneurial activities. The occurrence and development of entrepreneurial activity requires an integrated combination of elements. Financial strength, degree of openness, and vitality of innovation had the most substantial effect on the interactions among other factors, indicating that financing, access to international markets, and level of innovation were essential elements affecting the development of entrepreneurial activities. Regulating the conditions of other factors based on the satisfaction of such factors had a magnifying effect on the promotion of entrepreneurial activity. The economic foundation and the degree of informationization also showed strong synergy with other factors, indicating that the local environment for economic development and the efficiency of circulation of knowledge and information had a catalytic effect on entrepreneurial activities. Enhancing 
the level of development of such factors can have a qualitative and efficiency-enhancing effect on entrepreneurial activity. In addition, interactions between industrial structure, market demand, and other factors led to enhancement, indicating that optimizing the economic structure, industrial upgrading, and a strong consumer market demand all had a positive impact on the development of entrepreneurial activities; its two-factor synergy was stronger than the explanatory power of a single factor.

2001

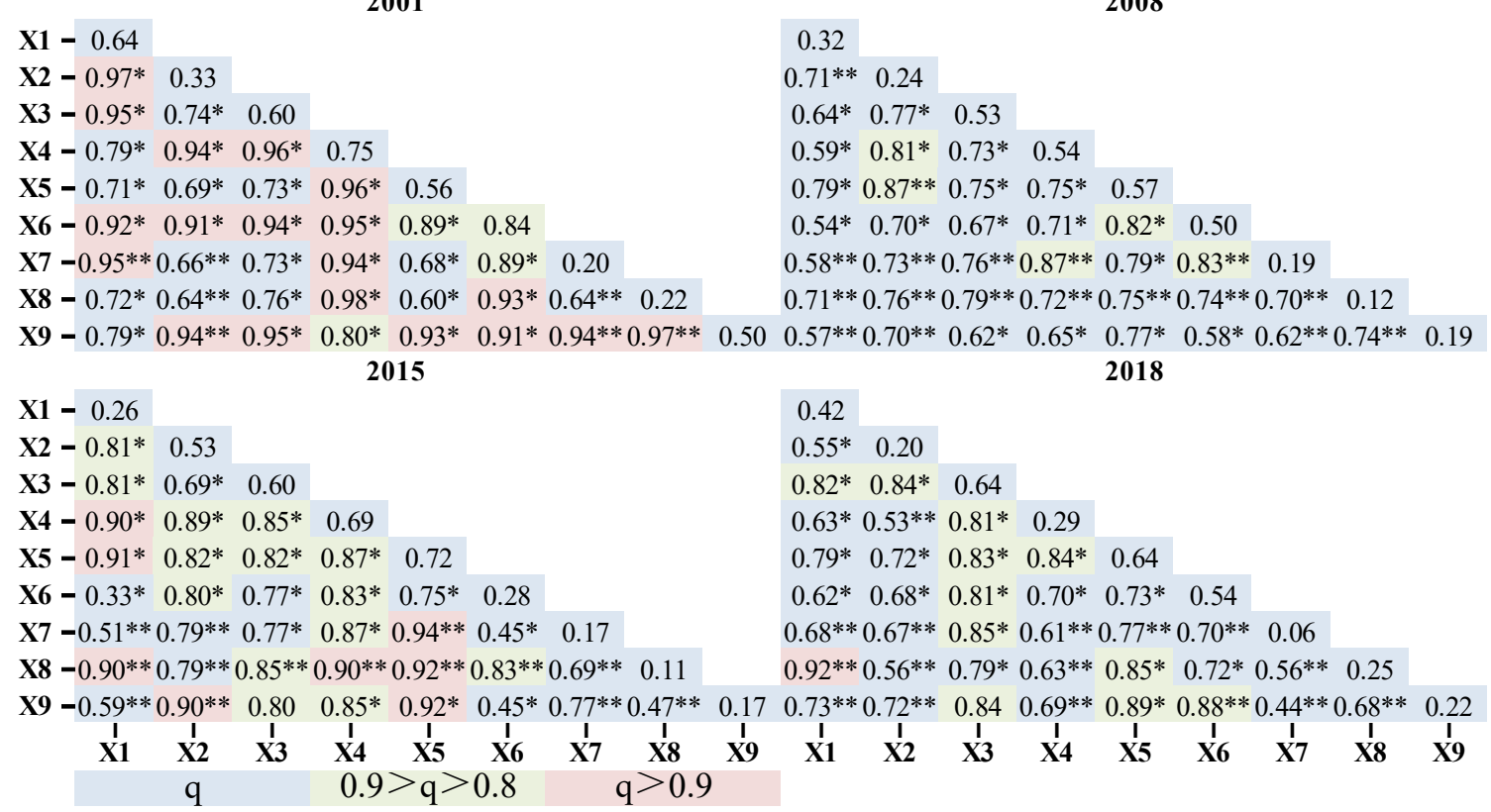

Figure 7. Results of interactions between factors influencing entrepreneurial activities in the Yangtze River Delta. Note: * and ** indicate "Enhance, bi" and "Enhance, nonlinear", respectively. Per capita GDP $(X 1)$, the ratio of the output of tertiary industry $(X 2)$, the year-end loan balance of financial institutions per capita (X3), the total ratios of imports and exports to GDP (X4), the total number of postal and telecommunications businesses per capita (X5), total retail sales of consumer goods per capita (X6), the density of the highway network (X7), the ratio of employees at the end of the year (X8), the number of patents granted per 10,000 people (X9).

\subsubsection{Analysis of Impact Mechanism}

We used the above quantitative examination of the leading factors and their interactions as they affected entrepreneurial activities in the Yangtze River Delta in order to analyze the internal mechanism driving entrepreneurial activities. The aim was to provide a decision-making reference for creating a suitable external environment for "mass entrepreneurship and innovation".

(1) Financial strength is the essential condition determining entrepreneurial activities. Funding is the cornerstone of entrepreneurial activities, and the basis for ensuring that all innovative thinking and ideas are transformed into material conditions. Funds to enable entrepreneurs to carry out their activities are usually provided as bank loans [58], and the year-end loan balance of financial institutions per capita is an important indicator of the regional financial environment, which can reflect the ease of obtaining financial support for entrepreneurial activities. The greater the financial strength, the looser the financial policy environment in the region, which helps entrepreneurs solve financial problems, obtain investments and other resources, and ensure the smooth development of entrepreneurial activities. In addition, the latter often emphasize entrepreneurial opportunities, and transforming new formats and ideas into a commercial format is an important means of achieving entrepreneurial success and maintaining a competitive edge. Therefore, strong financial support can 
provide timely means to support entrepreneurial activities, which is a basic element for maintaining the vitality of regional entrepreneurship. Our study showed that financial strength has a high single-factor explanatory power for entrepreneurial activities and is generally conducive to the efficiency of the other driving factors.

(2) The degree of informationization is crucial in determining the level of entrepreneurial activities. The 21st century is the era of informationization and networking. For entrepreneurial activities in these times, the degree of informationization determines the ability of a region to utilize and deploy resources. The greater the number of postal and telecommunications businesses per capita, the more developed regional informationization is, and the greater the investment in informationization. A high level of informationization is not only conducive to accelerating the efficient circulation of knowledge and the other elements of innovation and promoting the flow and dissemination of entrepreneurial resources through social networks but is also conducive to local entrepreneurs getting a timely and practical grasp of the relevant regional policies and market information so that they can share off-site sources of entrepreneurship and innovation. This can also optimize the incubation of the local entrepreneurial platform and policy environment, making the area suitable for sources of information and entrepreneurial innovation. The degree of informationization has increasingly fluctuated in its effects on the entrepreneurial activities in the Yangtze River Delta. The single-factor explanatory power rose from 0.5589 in 2001 to 0.6428 in 2018. Interactions with other factors also showed strong synergistic determinism.

(3) Economic foundation and vitality of innovation are synergistic factors affecting entrepreneurial activities. The former reflects the overall developmental environment of a given place: the higher the level of economic development, the better the overall developmental environment of a region and the better the conditions for obtaining various advantageous resources. However, this does not imply a higher level of entrepreneurship. Studies have confirmed that, with increasing levels of economic development in developing countries, entrepreneurship has not shown the same trend of substantial increase. However, with the growth of large and medium-sized enterprises, the rapid development of regional economics can provide more employment opportunities. A continual rise in wages motivates potential entrepreneurs to avoid risks and choose employment [58]. In addition, the vitality of innovation represented by the number of patents granted per 10,000 people did not have a strong explanatory power for entrepreneurial activities in the Yangtze River Delta region, because regions with a strong vitality of innovation struggle to implement entrepreneurial activities owing to widespread problems in the developmental environment or insufficient entrepreneurial support, such as a lack of funds. These results indicated that only when the overall level of regional development is high, the vitality of innovation is solid and other factors are simultaneously available do all these factors play a synergistic role in promoting entrepreneurial activities.

(4) Openness and market demand also promote entrepreneurial activities. The element of transparency, characterized by the ratio of total foreign trade imports and exports to GDP, reflects the level of openness of regional development to international markets. The higher the degree of opening up, the more conducive the given region is to expanding the consumer market for local products. Harmony with the global market is conducive to the dissemination and spillover of new knowledge, technologies, and formats, provides potential local entrepreneurs with new ideas and skills for entrepreneurship, and enhances its vitality. The total retail sales of consumer goods per capita reflects the dynamism of the regional economy and the level of consumption and also represents regional market demand. The higher the market demand, the stronger the vitality of the regional economy, the more frequent the circulation of factors, the more urgent the need for new products and technologies, and the stronger the promotion of innovation and entrepreneurial activities. We found that the impact of regional openness and market demand on entrepreneurial activities in 
the study area passed the $10 \%$ significance test. The indices of the explanatory power of openness and other factors in 2001 and 2015 were all above 0.8 .

\section{Discussion}

\subsection{Comparison of Spatial Differentiation in Entrepreneurial Platforms and Activities}

The occurrence and development of entrepreneurial activities are influenced and guided by policies, platforms, the development environment and other conditions. Moreover, the essence of entrepreneurial activities is spontaneous market behavior, whose spatial distribution exhibits a certain randomness owing to a large volume of data relating to regional entrepreneurial activity. However, few platforms are available for entrepreneurial innovation in various regions and are thus easy to extract and describe. Academic research has paid little attention to entrepreneurial activities, and many researchers have chosen platforms for entrepreneurial innovation as the objects of their research. Although these platforms play an important guiding role in the spatial distribution of entrepreneurial activities, whether they can characterize their distribution effectively remains to be verified.

We compared the results of this study with those reported by Wei Sheng et al. [26], who used venture capital institutions and entrepreneurial platforms as research objects in the same region investigated in this study. Overall, the spatial layout of the latter was consistent with that of the startups. However, the local spatial layout of venture capital institutions was more consistent with the spatial distribution of startups than that of entrepreneurial platforms because the government had promoted the construction of entrepreneurial platform, while the layout of venture capital institutions was more a function of market behavior. The spatial distribution of venture capital institutions driven by market forces can more truly reflect startups' spatial distribution, which represents market behavior. In addition, the spatial distributions of both venture capital institutions and entrepreneurial platforms were relatively limited, and the promotion of entrepreneurial activities was more localized. In addition to the influence of institutions and platforms, entrepreneurial activities were affected by the overall development environment of the region. A region with an excellent entrepreneurial climate can yield spatial spillover effects in surrounding areas. The development of the Yangtze River Delta region, as influenced by the entrepreneurial environment of cities such as Shanghai and Suzhou, led to the formation of the high-density entrepreneurial cluster of Shanghai-Suzhou-Wuxi-Changzhou around it. The spatial spillover effect of entrepreneurial activities is difficult to reflect in the layout of entrepreneurial institutions and platforms.

\subsection{Driving Mechanism of Entrepreneurial Activities Has Multiple Characteristics}

Revealing the driving mechanism of regional entrepreneurial activities is conducive to formulating policies for enhancing regional entrepreneurial vitality. However, studies analyzing the driving mechanism of entrepreneurial activities have usually focused on a single factor while ignoring the interaction between other factors $[20,32,58,59]$. We used a geographic detector model to reveal the factors affecting the spatial differentiation of entrepreneurial activities in the Yangtze River Delta. Traditional single-factor detection was supplemented by interactions among elemental combinations for further analysis. The results showed that a variety of influential factors generally exhibited both dual-factor and non-linear enhancement, indicating that the combination of factors enhanced the explanatory power of the spatial differentiation of entrepreneurial activities. That is, the driving mechanism of entrepreneurial activities had multiple characteristics. Therefore, future studies should pay attention to a comprehensive analysis of multi-factor combinations in order to guide the formulation of relevant policies and promote more comprehensive development of local entrepreneurial activities.

China is in transition from factor-driven to innovation-driven development, and the Yangtze River Delta region is one of the most economically developed regions in the country, whose entrepreneurial activities and economic vitality are distinctive signs of China's innovative economy. This study found that the year-end loan balances per capita of 
financial institutions showed strong explanatory power in both one-way analysis and twoway interaction, i.e., financial strength has played an extremely important and fundamental role in entrepreneurial activities in the Yangtze River Delta, a finding consistent with those of Lopes et al. [44] and Singh et al. [60] on entrepreneurial activities in Asia. This is due to the fact that starting or continuing a business in Asian countries often involves the cumbersome process of obtaining credit from financial institutions, and since finance is the cornerstone of entrepreneurial activity, the more lenient the financial conditions, the more favorable the entrepreneurial activity. In addition, regarding the impact of openness on entrepreneurial activity, a study by Lopes et al. [44] found that participation in globalization and the opening up of new markets leads to more efficient foreign firms stealing markets from a country, resulting in the formation of monopolies in the domestic market and reducing entrepreneurial dynamism in related industries. However, this paper reaches the opposite conclusion, namely, that greater openness is conducive to promoting entrepreneurial activity. This is because Lopes et al.'s study was conducted over a short time period, while this study was conducted over a long time range of nearly 20 years. Thus, the findings of these two differentiated studies on the impact of openness on entrepreneurial activity over short and long time periods, respectively further confirm De Backer et al.'s [45] findings that the entry of foreign capital and foreign firms may have a negative impact on entrepreneurial activity in the short term but have the opposite effect in the long term.

\section{Conclusions}

From the perspective of geography, this paper extracts the data for all startups from 2001-2018 from the database of industrial and commercial enterprises, reveals the spatially divergent characteristics of entrepreneurial activities and their correlation characteristics at municipal scale in the economically heavily developed Yangtze River Delta, over the past 20 years with the help of exploratory spatial analysis, and explores the characteristics of factor combinations affecting entrepreneurial activities in this region by means of singlefactor analysis and two-factor interaction analysis using the geographical detector. Our study found that, since the beginning of the 21st century, entrepreneurial activities in the Yangtze River Delta have been intense and have undergone a stable period of slow growth (2001-2013), followed by one of dynamic, rapid growth (2014-2018). The growth trend of entrepreneurial activities was found to be closely related to the macroeconomic background and relevant national policies.

In the past 18 years, the spatial density distribution of startups in the Yangtze River Delta increased. The state of agglomeration of these startups showed developmental trends of concentration and diffusion, while forming a dotted pattern of agglomeration centered on the provincial capital cities of Nanjing, Hangzhou, and Hefei. The entrepreneurial activities of cities in the Yangtze River Delta exhibited significant characteristics of spatial correlation. Over time, the state of high-value agglomeration of entrepreneurial activities has become relatively stable, and the trend of low-value agglomeration has gradually been weakening. Financial strength, degree of informationization, economic foundation, vitality of innovation, degree of openness, and market demand are the main factors affecting entrepreneurial activities in the Yangtze River Delta. This study confirmed that entrepreneurial activities have significant spatial correlation and that areas with high entrepreneurial vitality have a radiating effect on entrepreneurial activities in neighboring areas. In addition, our study found that the factors affecting entrepreneurial activities are multifaceted and that policy makers should promote entrepreneurial activities through multiple channels from a holistic perspective. Our study adds to the understanding of the spatial proximity characteristics of long time series of entrepreneurial activities at municipal scales in developing countries and reveals the multi-factor combination of characteristics that drive entrepreneurial activities.

The spatial distribution of entrepreneurial activities in the Yangtze River Delta region remains uneven. Large cities have spatial imbalances, such as "shadow zone" of entrepreneurial activities. In the context of implementing the national development strategy of regional integration in the Yangtze River Delta region, particular attention should 
be paid to the following points in the future in order to promote the development of entrepreneurial activities: (1) There is a need to strengthen the leadership of central cities and expand their spillover effects. The development status of entrepreneurial activities in the Yangtze River Delta should be combined with those of the provincial capital cities of Nanjing, Hangzhou, and Hefei as well as the Shanghai-Suzhou-Wuxi-Changzhou metropolitan belt as cluster centers, with the aim of promoting the orderly spillover and dissemination of factors affecting entrepreneurial innovation, including talent, information, capital, and policies, in order to stimulate entrepreneurial vitality and economic potential in the surrounding regions and enhance the level of regional entrepreneurial and collaborative development. (2) The role of entrepreneurial platforms needs greater attention to be paid to it and the layout of the platforms needs to be optimized. Led by venture capital institutions and entrepreneurial platforms, full play needs to be given to the initiative of provincial governments in the overall deployment of resources. The layout of the platforms of entrepreneurial depressions in northern Jiangsu, southwestern Zhejiang, and northern Anhui needs to be addressed, and traffic corridors should be used to promote the construction of channels of entrepreneurial innovation, such as G60. An entrepreneurial network of platforms needs to be built in the Yangtze River Delta. (3) Entrepreneurial vitality needs to be strengthened, and there needs to be a greater ability to take advantage of scientific and technological achievements. The construction of a soft environment for policies, finance, services, and commerce in various regions needs to be strengthened in order to provide a suitable external environment for the growth and development of enterprises, to increase investment in technological research and development and cultivate high-tech talent, and to continue to inject renewed energy into entrepreneurial activities. An entrepreneurial system that integrates production, education, and research needs to be constructed in order to ensure proper connections among basic and applied research, industrialization, and innovation and entrepreneurship. (4) Central government needs to continue to open up the economy and use entrepreneurial activities to boost the dual-cycle developmental pattern. Under the leadership of the "Belt and Road" Initiative, an open regional economic system needs to be built, and the development opportunities afforded by open cooperation platforms such as the China International Import Expo need to be exploited in order to connect with overseas cooperation parks for the benefit of production. The development of entrepreneurial activities based on domestic and overseas markets or resources also needs to be promoted, in order to integrate them efficiently into the dual-cycle developmental pattern within China and across the world.

Since the acquisition of data for the latest year has not yet been implemented, the data have not been updated to 2020 due to objective reasons, which is a shortcoming, and therefore further supplementary studies will need to be conducted to update the data when new data become available. In addition, entrepreneurial activities involve many developmental stages, such as the birth, growth, evolution, and death of startups. Due to limitations of space, this paper has focused on entrepreneurial activities in their initial stages only, whereas their subsequent evolution is also important for their overall development. At the same time, the choice of spatial location for startups is an essential factor in the formation of industrial clusters, and profoundly affects their prospects for success. Future studies should also take into account the impact of startups' locations on the growth and death of enterprises. Since the end of 2019, the outbreak of the COVID-19 pandemic, which seriously affected the normal functioning of the social economy, was an abnormal stage in the evolution of entrepreneurial activities. The trends of entrepreneurial activities during and since the COVID-19 pandemic will be studied and refined in future research.

Author Contributions: Conceptualization, H.Z. and W.C.; methodology, H.Z.; software, H.Z.; validation, H.Z., W.C. and Z.L.; formal analysis, H.Z.; data curation, H.Z.; writing-original draft preparation, H.Z.; writing-review and editing, H.Z.; visualization, W.C.; supervision, W.C.; project administration, W.C.; funding acquisition, Z.L. All authors have read and agreed to the published version of the manuscript. 
Funding: This research was funded by the National Natural Science Foundation of China (Grants Nos. 41901154 and 42130508), the Strategic Priority Research Program of the Chinese Academy of Sciences (Grant No. XDA20010102), and the Second Tibetan Plateau Scientific Expedition and Research Program (Grant No. 2019QZKK1007).

Data Availability Statement: The new data created in this study are available on request.

Acknowledgments: The authors would like to thank the anonymous reviewers for their comments and suggestions which contributed to the further improvement of this paper.

Conflicts of Interest: The authors declare no conflict of interest.

\section{References}

1. Bishop, P.; Shilcof, D. The spatial dynamics of new firm births during an economic crisis: The case of Great Britain, $2004-2012$. Entrep. Reg. Dev. 2017, 29, 215-237. [CrossRef]

2. Van Stel, A.; Suddle, K. The impact of new firm formation on regional development in the Netherlands. Small Bus. Econ. 2008, 30, 31-47. [CrossRef]

3. Yao, L.; Hu, Y. The impact of urban transit on nearby startup firms: Evidence from Hangzhou, China. Habitat Int. 2020, 99, 102155. [CrossRef]

4. Wang, Z.; Wei, W. Regional economic resilience in China: Measurement and determinants. Reg. Stud. 2021, 55, 1228-1239. [CrossRef]

5. Fu, W. Industrial clusters as hothouses for nascent entrepreneurs? The case of Tianhe Software Park in Guangzhou, China. Ann. Reg. Sci. 2016, 57, 253-270. [CrossRef]

6. Alessandra, C.; Gianluca, O.; Francesco, Q. Local knowledge composition and the emergence of entrepreneurial activities across industries: Evidence from Italian NUTS-3 regions. Small Bus. Econ. 2021, 56, 613-635.

7. Lee, J.; Xu, J. Why do businesses grow faster in urban areas than in rural areas? Reg. Sci. Urban Econ. 2020, 81, 103521. [CrossRef]

8. Mark, P.; Shawn, M.; Amanda, L. Firm formation and survival in the shale boom. Small Bus. Econ. 2020, 55, 975-996.

9. Pan, F.; Yang, B. Financial development and the geographies of startup cities: Evidence from China. Small Bus. Econ. 2019, 52, 743-758. [CrossRef]

10. Michael, F.; Pamela, M. The effect of new business formation on regional development over time: The case of Germany. Small Bus. Econ. 2008, 30, 15-29.

11. Lucia, N.; Pia, N.; Hans, W.; Sofia, W. Amenities and new firm formation in rural areas. J. Rural Stud. 2021, 85, 32-42.

12. Udo, B.; Reinhold, G. Regional patterns and determinants of birth and survival of new firms in Western Germany. Entrep. Reg. Dev. 2007, 19, 293-312.

13. Oyarzo, M.; Romaní, G.; Atienza, M.; Lufín, M. Spatio-temporal dynamics in municipal rates of business start-ups in Chile. Entrep. Reg. Dev. 2020, 32, 677-705. [CrossRef]

14. Jessie, P.; Poon, H.; Diep, T.; Deborah, N. Social capital and female entrepreneurship in rural regions: Evidence from Vietnam. Appl. Geogr. 2012, 35, 308-315.

15. Patrick, A.; Richard, F.; Karen, K.; Charlotta, M. The city and high-tech startups: The spatial organization of Schumpeterian entrepreneurship. Cities 2019, 87, 121-130.

16. Cheng, S.; Li, H. Spatially Varying Relationships of New Firm Formation in the United States. Reg. Stud. 2011, 45, 773-789. [CrossRef]

17. Cissé, I.; Dubé, J.; Brunelle, C. New business location: How local characteristics influence individual location decision? Ann. Reg. Sci. 2020, 64, 185-214. [CrossRef]

18. Gao, J.; Feng, Y. Economic Transition, Firm Dynamics, and Restructuring of Manufacturing Spaces in Urban China: Empirical Evidence from Nanjing. Prof. Geogr. 2017, 69, 504-519. [CrossRef]

19. Fu, W. Local entrepreneurship and cluster restructuring: An integrative theoretical perspective. Sci. Geogr. Sin. 2016, 36, 715-723. (In Chinese)

20. Sun, B.; Zhu, P.; Li, W. Cultural diversity and new firm formation in China. Reg. Stud. 2019, 53, 1371-1384. [CrossRef]

21. Wang, C.; Lin, G. Geography of knowledge sourcing, heterogeneity of knowledge carriers and innovation of clustering firms: Evidence from China's software enterprises. Habitat Int. 2018, 71, 60-69. [CrossRef]

22. Hojnik, B.B.; Crnogaj, K. Social impact, innovations, and market activity of social enterprises: Comparison of European countries. Sustainability 2020, 12, 1915. [CrossRef]

23. Ács, Z.J.; Szerb, L.; Ortega-Argilés, R.; Aidis, R.; Coduras, A. The regional application of the global entrepreneurship and development index (GEDI): The case of Spain. Reg. Stud. 2015, 49, 1977-1994. [CrossRef]

24. Yam, R.C.M.; Lo, W.; Tang, E.P.Y.; Lau, A.K.W. Analysis of sources of innovation, technological innovation capabilities, and performance: An empirical study of Hong Kong manufacturing industries. Res. Policy 2011, 40, 391-402. [CrossRef]

25. Tang, D.; Mao, M.; Shi, J.; Hua, W. The Spatio-Temporal Analysis of Urban-Rural Coordinated Development and Its Driving Forces in Yangtze River Delta. Land 2021, 10, 495. [CrossRef] 
26. Wei, S.; Wang, L.; Cao, J. Spatial Distribution Characteristics and Impact Factors of Urban Innovative Capacities in the Yangtze River Delta Region: A Perspective from the "Business Startups and Innovation" Institutions and Platforms. Econ. Geogr. 2020, 40, 36-42. (In Chinese)

27. Carree, M.; Thurik, A. The lag structure of the impact of business ownership on economic growth in OECD countries. Small Bus. Econ. 2007, 30, 101-110. [CrossRef]

28. Fritsch, M.; Wyrwich, M. The effect of entrepreneurship on economic development-An empirical analysis using regional entrepreneurship culture. J. Econ. Geogr. 2017, 17, 157-189. [CrossRef]

29. Kim, J. Does foreign direct investment matter to domestic entrepreneurship? The mediating role of strategic alliances. Glob. Econ. Rev. 2019, 48, 303-319. [CrossRef]

30. Shweta, G.; Madan, L. Entrepreneurship and Economic Growth: Evidence from G-20 Economies. J. East-West Bus. 2021, 27, 140-159.

31. Prieger, J.E.; Bampoky, C.; Blanco, L.R.; Liu, A. Economic growth and the optimal level of entrepreneurship. World Dev. 2016, 82, 95-109. [CrossRef]

32. Li, L.; Niu, N.; Li, X. Factors Affecting the Long-Term Development of Specialized Agricultural Villages North and South of Huai River. Land 2021, 10, 1215. [CrossRef]

33. Beugelsdijk, S.; Noorderhaven, N. Entrepreneurial attitude and economic growth: A cross-section of 54 regions. Ann. Reg. Sci. 2004, 38, 199-218. [CrossRef]

34. Alvarez, C.; Urbano, D.; Coduras, A. Environmental conditions and entrepreneurial activity: A regional comparison in Spain. Int. J. Phys. Distrib. Logist. Manag. 2011, 18, 120-140.

35. Sabrina, F.; Marina, J. Local culture as a context for entrepreneurial activities. Eur. Plan. Stud. 2017, 25, 1556-1574.

36. Daymard, A. Determinants of female entrepreneurship in India. In OECD Economics Department Working Papers, No. 1191; OECD Publishing: Paris, France, 2015.

37. Kaufmann, D.; Kraay, A.; Mastruzzi, M. The Worldwide Governance Indicators: Methodology and Analytical Issues. Hague J. Rule Law. 2017, 3, 220-246. [CrossRef]

38. Khyareh, M.; Amini, H. Governance Quality, Entrepreneurship and Economic Growth. J. Compet. 2021, 13, 41-64. [CrossRef]

39. Nwachukwu, C.; Chladkova, H.; Olatunji, F. Strategy formulation process and innovation performance nexus. Int. J. Qual. Res. 2018, 12, 147-164.

40. Pawitan, G.; Widyarini, M.; Nawangpalupi, C. Moderating effect of demographic factors and entrepreneurial phase on the relationship between entrepreneurial competencies and innovation of ASEAN entrepreneurs. Pert. J. Soc. Sci. Hum. 2018, 26, 151-166.

41. Pinto, B.; Lopes, J.; Carvalho, C.; Vieira, B.; Lopes, J. Education as a key to provide the growth of entrepreneurial intentions. Edu. Train. 2021, 63, 809-832. [CrossRef]

42. Guerrero, M.; Peña-Legazkue, I. The effect of intrapreneurial experience on corporate venturing: Evidence from developed economies. Int. Entrep. Manag. J. 2013, 9, 397-416. [CrossRef]

43. Dadzie, K.; Amponsah, D.; Dadzie, C.; Winston, E. How Firms Implement Marketing Strategies in Emerging Markets: An Empirical Assessment of the 4a Marketing Mix Framework. J. Mark. Theory Pract. 2017, 25, 234-256. [CrossRef]

44. Lopes, J.; Oliveira, M.; Silveira, P.; Farinha, L.; Oliveira, J. Business Dynamism and Innovation Capacity, an Entrepreneurship Worldwide Perspective. J. Open Innov. Technol. Mark. Complex. 2021, 7, 94. [CrossRef]

45. De Backer, K.; Sleuwaegen, L. Does foreign direct investment crowd out domestic entrepreneurship? Rev. Ind. Organ. 2003, 22, 67-84. [CrossRef]

46. Salman, D. What is the role of public policies to robust international entrepreneurial activities on economic growth? Evidence from cross countries study. Fut. Bus. J. 2016, 2, 1-14. [CrossRef]

47. National Bureau of Statistics. Available online: http://www.stats.gov.cn (accessed on 10 December 2021).

48. Han, B.; Ma, Z.; Liu, Y.; Wang, M.; Lin, Y. Effect of Urban-Rural Income Gap on the Population Peri-Urbanization Rate in China. Land 2021, 10, 1255. [CrossRef]

49. Li, H.; Song, W. Cropland Abandonment and Influencing Factors in Chongqing, China. Land 2021, 10, 1206. [CrossRef]

50. Spigel, B.; Harrison, R. Toward a process theory of entrepreneurial ecosystems. Strateg. Entrep. J. 2018, 12, 151-168. [CrossRef]

51. Wang, J.; Li, X.; Christakos, G.; Liao, Y.; Zhang, T.; Gu, X.; Zheng, X. Geographical detectors-based health risk assessment and its application in the neural tube defects study of the Heshun region, China. Int. J. Geogr. Inf. Sci. 2010, 24, 107-127. [CrossRef]

52. Huggins, R.; Prokop, D. Network structure and regional innovation: A study of university-industry ties. Urban Stud. 2016, 54, 931-952. [CrossRef]

53. Daniel, C. What is a startup firm? A methodological and epistemological investigation into research objects in economic geography. Geoforum 2019, 107, 77-87.

54. Yang, C.; Xie, S.; Gan, C. Spatial Differences and Its Influencing Factors of Entrepreneurship Activity of Chinese Private Enterprises. Econ. Geogr. 2021, 41, 141-148. (In Chinese)

55. Huggins, R.; Prokop, D.; Thompson, P. Entrepreneurship and the Determinants of Firm Survival within Regions: Human Capital, Growth Motivation and Locational Conditions. Entrep. Reg. Dev. 2017, 29, 357-389. [CrossRef]

56. Cruz, S.; Teixeira, A. Spatial analysis of new firm formation in creative industries before and during the world economic crisis. Ann. Reg. Sci. 2021, 67, 385-413. [CrossRef] 
57. Wennekers, S.; Wennekers, A.; Thurik, R. Nascent Entrepreneurship and the Level of Economic Development. Small Bus. Econ. 2005, 24, 293-309. [CrossRef]

58. Ding, Y.; Zhu, H.; He, Q. The Regional Differences and Determinants of Entrepreneurship in Guangdong Province: Based on Spatial Autocorrelation Analysis. Econ. Geogr. 2017, 37, 92-98. (In Chinese)

59. Farinha, L.; Ferreira, J.; Nunes, S.; Ratten, V. Conditions Supporting Entrepreneurship and Sustainable Growth. Int. J. Soc. Ecol. Sustain. Dev. 2017, 8, 67-86. [CrossRef]

60. Singh, S.; Pravesh, R. Entrepreneurship Development in India: Opportunities and Challenges. Splint Int. J. Prof. 2017, 4, 75-81. 